УДК 33

DOI $10.21661 / \mathrm{r}-472729$

\title{
O.A. Федосова
}

\section{НЕДОСТАТКИ ПРАВИЛ РЕГУЛИРОВАНИЯ ТРАНСФЕРТНОГО ЦЕНООБРАЗОВАНИЯ В РОССИЙСКОЙ ФЕДЕРАЦИИ И ПУТИ ИХ СОВЕРШЕНСТВОВАНИЯ}

\begin{abstract}
Аннотация: трансфертное ценообразование является эффективным инструментом повышения конкурентоспособности вертикально-интегрированных компаний и глобальных цуепочек стоимости. В данной статье рассмотреньл преимущества и недостатки регулирования трансфертного иченообразования $в$ России, приведены примеры, из которых следует, что налоговые органы не заинтересованы в содействии компаниям. Приведены некоторые методы по усовериенствованию налогового законодательства.
\end{abstract}

Ключевые слова: трансфертное ченообразование, корпорация, трансфертные цуень, взаимосвязанные лица, транснациональные компании, налогообложение.

\section{O.A. Fedosova \\ DISADVANTAGES OF RULES OF REGULATION OF TRANSFER PRICING IN THE RUSSIAN FEDERATION AND WAYS OF THEIR IMPROVEMENT}

Abstract: transfer pricing is an effective way to rise a competitiveness of vertical integrated companies and global value chains. This article considers advantages and shortcomings in the regulation of transfer pricing in Russia, describes examples, which show that tax authorities are not interested in cooperation with companies. There are some methods for improving tax legislation.

Keywords: transfer pricing, corporation, transfer prices, interrelated companies, transnational companies, taxation. 
В Российской Федерации в 2012 году вступили в силу поправки, принятые для осуществления контроля над трансфертными ценами, - Федеральный закон №227-Ф3 от 18.07.2011 г. «О внесении изменений в отдельные законодательные акты Российской Федерации в связи с совершенствованием принципов определения цен для целей налогообложения». Однако, новые правила имеют ряд существенных недостатков.

В первую очередь нужно сказать о низком юридическом качестве данного Федерального закона №227-ФЗ. Во-первых, в тексте Ф3 содержатся достаточно широкие формулировки полномочий налоговых органов и судов. У крупного бизнеса это вызывает вполне объяснимые опасения, так как данный момент может повлечь возможность злоупотребления налоговыми органами. В определенных случаях они смогут по-своему трактовать нормы закона и даже компании, не являющиеся взаимосвязанными, вполне могут стать таковыми. Также в п. 7 ст. 105.1 НК РФ говорится, что суд может признать лица взаимозависимыми по основаниям, не предусмотренным НК РФ, если особенности отношений между этими лицами могут оказывать влияние на условия и (или) результаты сделок, совершаемых этими лицами.

Во-вторых, внесенные изменения никак не уменьшают тенденцию по усилению налогового бремени. Непонятно, например, почему взаимозависимые компании, в случае добровольного признания себя взаимозависимыми, вправе самостоятельно корректировать свои налоговые обязательства, однако, они не могут проводить симметричные корректировки, которые возможны только после проверки налоговыми органами. Отсутствие возможности самостоятельной симметричной корректировки может привести к двойному налогообложению.

Также в Ф3 присутствуют неопределенные формулировки, внутренние противоречия, использование большого объема экономических терминов без указания на их содержание.

Помимо этого, налоговые органы говорят о необходимости высокой детализации уведомлений, не ограничиваясь заполнением данных только о доходахрасходах и требуют заполнения данных в отношении каждой номенклатуры 
товаров, участвующих в сделке. А так как, крупные компании совершают сделки с большим объемом товаров, это может привести к выполнению большого объема работ, заполнению огромного количества листов в уведомлении и, соответственно, к большим трудовым и материальным затратам.

В правилах трансфертного ценообразования существуют и иные недочеты. Например, такие как:

- отсутствие механизма симметричных корректировок в случае добровольного признания сделки контролируемой и применения последствий такого признания;

- значительный временной разрыв в начислении налогов у одной стороны и права на симметричную корректировку с другой;

- большие экономические потери - налоговые санкции для предприятий составляют $40 \%$ от неуплаченной суммы налога.

Преимущества и недостатки трансфертного ценообразования

в Российской Федерации

\begin{tabular}{|l|l|}
\hline \multicolumn{1}{|c|}{ Преимущества } & \multicolumn{1}{|c|}{ Недостатки } \\
\hline $\begin{array}{l}\text { Исключение из сферы налогового контроля } \\
\text { участников консолидированных групп нало- } \\
\text { гоплательщиков и налогоплательщиков, не } \\
\text { имеющих обособленных подразделений на } \\
\text { территории других субъектов Федерации }\end{array}$ & $\begin{array}{l}\text { Контроль сделок между взаимозависимыми } \\
\text { лицами внутри страны }\end{array}$ \\
\hline $\begin{array}{l}\text { Наличие переходного периода: установле- } \\
\text { ние моратория на штрафные санкции и це- } \\
\text { новых порогов для контролируемых сделок }\end{array}$ & $\begin{array}{l}\text { Значительные налоговые санкции - } \\
\text { неуплаченной суммы налога, но не менее } \\
\text { 30 тыс. руб. }\end{array}$ \\
\hline $\begin{array}{l}\text { Близость к международным правилам регу- } \\
\text { лирования трансфертного ценообразования }\end{array}$ & $\begin{array}{l}\text { Несогласованность норм положений тамо- } \\
\text { женного регулирования и государственного } \\
\text { тарифного регулирования с нормами транс- } \\
\text { фертного ценообразования }\end{array}$ \\
\hline Наличие симметричных корректировок & $\begin{array}{l}\text { Значительный временной разрыв в начисле- } \\
\text { нии налогов у одной стороны сделки и } \\
\text { права на симметричную корректировку у } \\
\text { другой }\end{array}$ \\
\hline $\begin{array}{l}\text { Установление специальных субъектов нало- } \\
\text { гового контроля и специальных процедур } \\
\text { налогового контроля }\end{array}$ & $\begin{array}{l}\text { Отсутствие самостоятельной возможности } \\
\text { симметричной корректировки в случае доб- } \\
\text { ровольного признания сделки контролируе- } \\
\text { мой }\end{array}$ \\
\hline
\end{tabular}




\begin{tabular}{|c|c|}
\hline $\begin{array}{l}\text { Отсутствие практических возможностей } \\
\text { симметричных корректировок для ино- } \\
\text { странных контрагентов и представительств } \\
\text { иностранных компаний }\end{array}$ & $\begin{array}{l}\text { Возможность подписания предварительного } \\
\text { налогового соглашения, исключающего воз- } \\
\text { можность применения со стороны налого- } \\
\text { вых органов налоговых санкций и позволя- } \\
\text { ющего заранее }\end{array}$ \\
\hline \multirow[t]{2}{*}{ Преимущества } & Недостатки \\
\hline & $\begin{array}{l}\text { Согласовать с ним порядок определения цен } \\
\text { и их проверки на соответствие рыночному } \\
\text { уровню }\end{array}$ \\
\hline $\begin{array}{l}\text { Исследование существа сделки в процессе } \\
\text { налогового контроля - приоритет содержа- } \\
\text { ния над формой }\end{array}$ & $\begin{array}{l}\text { Наличие множества разночтений, техниче- } \\
\text { ских неясностей и несогласованности в нор- } \\
\text { мах закона }\end{array}$ \\
\hline $\begin{array}{l}\text { Увеличение количества методов определе- } \\
\text { ния соответствия трансфертных цен рыноч- } \\
\text { ному уровню }\end{array}$ & $\begin{array}{l}\text { Перенос основного бремени доказывания на } \\
\text { плечи налогоплательщика }\end{array}$ \\
\hline $\begin{array}{l}\text { Закрепление состава и иерархии источников } \\
\text { информации о ценах }\end{array}$ & $\begin{array}{l}\text { Увеличение расходов на налоговое админи- } \\
\text { стрирование у налогоплательщиков }\end{array}$ \\
\hline $\begin{array}{l}\text { Исключение из числа контролируемых сде- } \\
\text { лок бартерных операций и сделок с отклоне- } \\
\text { нием цены более чем на } 20 \%\end{array}$ & $\begin{array}{l}\text { Противоречия между правилами трансферт- } \\
\text { ного ценообразования и существующими } \\
\text { нормами налогового регулирования }\end{array}$ \\
\hline
\end{tabular}

Из вышеперечисленного можно сделать вывод о невысокой незаинтересованности налоговых органов в соглашениях по ценообразованию и содействию налогоплательщику.

За несколько лет действия правил налогообложения взаимосвязанных компаний, практика их применения говорит о необходимости усовершенствования налогового контроля за использованием трансфертных цен.

В связи с выявленными недостатками налоговой системы Российской Федерации предлагаются следующие методы совершенствования регулирования трансфертного ценообразования в Российской Федерации:

1) пересмотр требований к раскрытию информации о контролируемых сделках, содержащихся в документации о ценообразовании в целях налогового контроля и в уведомлениях о контролируемых сделках, в том числе с учетом предложений, опубликованных ОЭСР в рамках Плана BEPS;

2) уточнение порядка применения методов определения цен для целей налогообложения, предусмотренных главой 14.3 Налогового кодекса Российской Федерации; 
3) уточнение условий, при которых внешнеторговые сделки товарами, которые составляют основные статьи экспорта Российской Федерации (к примеру, нефть и товары, выработанные из нефти, черные и цветные металлы, драгоценные камни, минеральные удобрения, драгоценные металлы), признаются контролируемыми;

4) пересмотр полномочий Федеральной налоговой службы и территориальных налоговых органов при реализации положений Налогового кодекса Российской Федерации.

\section{Список литературы}

1. Налоговый кодекс Российской Федерации часть первая от 31.07.1998 ст. 105 (с изменениями на 1 мая 2016 года) [Электронный ресурс]. - Режим доступа: http://base.consultant.ru

2. Федеральный закон от 18 июля 2011 г. №227-Ф3 «О внесении изменений в отдельные законодательные акты Российской Федерации в связи с совершенствованием принципов определения цен для целей налогообложения» [Электронный ресурс]. - Режим доступа: http://base.garant.ru/

\section{References}

1. Nalogovyi kodeks Rossiiskoi Federatsii chast' pervaia ot 31.07.1998 st. 105 (s izmeneniiami na 1 maia 2016 goda). Retrieved from http://base.consultant.ru

2. Federal'nyi zakon ot 18 iiulia 2011 g. 227-FZ "O vnesenii izmenenii v otdel'nye zakonodatel'nye akty Rossiiskoi Federatsii v sviazi s sovershenstvovaniem printsipov opredeleniia tsen dlia tselei nalogooblozheniia". Retrieved from http://base.garant.ru/

Федосова Ольга Александровна - студентка ФГАОУ ВО «Национальный исследовательский ядерный университет «МИФИ», Россия, Москва.

Fedosova Olga Alexandrovna - student of the FSAEI of HE «National Nuclear Research University «MEPhI», Russia, Moscow. 